\title{
Dental tourists: treat, re-treat or do not treat?
}

\author{
Shoukat Ashiti*1 and Catherine Moshkun²
}

\section{Key points}

Raises clinicians' awareness of healthcare tourism and the reasons behind it.

Highlights complications arising for patients from treatment abroad, and the difficulties in treating these patients and possible clinical and medicolegal issues dentists may face.
Highlights the impact of medical tourism on UK healthcare.

\begin{abstract}
Many UK patients in the search for their perfect smile have now decided to have their dental treatment abroad, the main reasons being that they believe they can have the same treatment but at a much lower price. With many overseas clinics offering treatment packages that also include a holiday, dental tourism seems an opportunity not to be missed. Although not always the case, some treatments unfortunately do not go to plan, often leaving distraught patients and their apprehensive dentists in a difficult situation. This article will discuss the reasons behind dental tourism and if the health system has contributed to the increasing demand for dental tourism. We will touch on the impact dental tourism has had on UK dentistry and if the NHS should be responsible for handling the consequences of any failed or incomplete dental treatment carried out abroad. It will also put the spotlight on dentists' responsibilities and to what extent they should treat these patients, as these cases can leave clinicians in primary and secondary care in a challenging predicament, not only clinically but also ethically and medico-legally.
\end{abstract}

\section{Introduction}

Many dentists will be able to relate to the situation where their patient has travelled abroad to undergo dental treatment. In some cases, they will return without complications; however, how should dentists manage patients where this treatment has not gone to plan? If a patient presented with a numb lip following implant placement abroad, or with implants of unknown type that have not been restored, how are we as professionals expected to handle this? There are various reasons why patients are travelling abroad for their healthcare and it is undoubtedly impacting on dentistry, the NHS and clinicians, especially when patients return to the UK requiring remedial work. Dentists

${ }^{1}$ Postgraduate OMFS student, University Dental Hospital of Manchester, Higher Cambridge Street, M15 6FD, UK; ${ }^{2}$ Speciality Dentist, University Dental Hospital of Manchester, Higher Cambridge Street, M15 6FD, UK. *Correspondence to: Shoukat Ashiti Email address: drshoukat@hotmail.com

Refereed Paper.

Accepted 27 August 2020

https://doi.org/10.1038/s41415-020-2591-6 are therefore increasingly faced with difficult situations where they feel the need to help these patients, who are often in pain, or upset with their new but failing dentition, yet they do not feel comfortable taking over treatment that has been started elsewhere.

\section{What is dental tourism?}

Medical, or dental tourism, is when patients travel abroad for the purpose of medical or dental treatment. In 2010, around 63,000 UK citizens travelled abroad for treatment. ${ }^{1}$ It has been reported that the number of Britons going abroad for treatment has increased significantly from 48,000 patients in 2014 to 144,000 in 2016. ${ }^{2}$ Also, it was reported that Medigo, which was a medical travel platform, had more than 350,000 visits a month by $2016,{ }^{3}$ and in 2015 , it was estimated that at least 190,000 patients were thinking of treatment abroad because of long NHS waiting lists. ${ }^{4}$ The estimated value of the medical tourism market worldwide was 60 billion US dollars in 2006, which increased to 100 billion US dollars in 2012. ${ }^{5}$ While patients from developing countries are keen to travel to the UK to access better quality health services, UK citizens are now willingly leaving the high-quality treatment in the UK in pursuit of cheaper treatment abroad. The majority access treatment in Asian countries such as India, Malaysia, Thailand and Singapore, and other Eastern European countries such as Hungary, Bulgaria and Romania. ${ }^{6,7,8}$

\section{What are the reasons behind dental tourism?}

According to the media, literature and websites of overseas dental practices, the main reasons for medical tourism were classified into pushing and pulling factors that drive patients' decisions for medical tourism; for example, quality, efficiency and hospital reputation were considered as pulling factors, while high-cost treatments, long waiting lists and lack of availability were the pushing reasons. ${ }^{9}$ Additionally, other reasons include patients travelling abroad for holidays, cultural reasons, reducing treatment timescale or the treatment option itself. ${ }^{8,10}$ It has been reported that some travel abroad because they do not 
trust NHS dentists and found some of the results 'amateurish', ${ }^{11}$ and they find it difficult to register with an NHS dentist. ${ }^{12,13}$ From a cultural point of view, this was more prevalent among immigrants. Some Gujaratis who were born in East Africa travelled to Gujarat for religious purposes and had treatment at the same time, whereas other Gujaratis followed the recommendation of a family member or a friend when seeking treatment. ${ }^{14} \mathrm{On}$ the other hand, immigrants in Canada were seeking treatment in their home country because of the lack of dental insurance and also looking for similar culture identity language. ${ }^{15}$ Interestingly, employment status in Canada has played an important part in reasons for seeking dental care abroad, as jobless individuals cannot have insurance, especially among females who are facing difficulties finding a job because of the labour market. ${ }^{15}$ Some patients may travel from the UK back to their home country for treatment, as they feel more comfortable and at ease in an environment of their own, and perhaps with a greater trust in the clinician. They also may prefer speaking in their mother language and having family members around in their home country during treatment. ${ }^{16}$ Timescales for treatment also play a role in influencing where patients choose to have their treatment. With dental implants, for example, although a patient may be eligible for implant funding on the NHS, this would involve the patient attending many appointments, including multidisciplinary consultations, imaging appointments, surgery itself and then restorative treatment. If they cannot afford private treatment in the UK, they may therefore opt instead for treatment abroad, where one clinician in a limited number of appointments can offer everything at a low price, thus obtaining the final result more quickly. It could also be that patients requesting a more controversial treatment option feel the need to travel abroad as clinicians in the UK may not feel comfortable in providing this, both ethically and medico-legally. For example, patients who do not like the colour or shape of their own natural teeth and are looking for a 'Hollywood smile' may be in search of a dentist who will provide extensive indirect restorations on their otherwise healthy teeth. Obtaining this kind of treatment may prove to be increasingly difficult as perhaps UK dentists are becoming more conservative in their treatment plans, due to the ever-increasing problem of 'defensive dentistry'. Some dentists will only undertake low-risk procedures in the hope of not being sued or receiving a complaint. ${ }^{17}$ Dental Protection carried out a survey of 1,000 dentists, which showed $89 \%$ were scared of being sued and $74 \%$ argued this impacted on their clinical practice. ${ }^{18}$ Increasing litigation and over-regulation has changed the perception of UK dentistry, to the extent that, at the Nobel Biocare Global Symposium, an American speaker said to a UK dentist that 'it's impossible to practise in the UK without fear of being sued, so fewer risks are taken. ${ }^{18}$ Therefore, perhaps these dentists would be reluctant to provide particular treatments which they felt were risky, thus forcing the patient to go elsewhere.

\section{Dentistry as a selling product}

Many foreign dental practices are enticing UK patients by advertising an attractive full package, including dental treatment with a holiday, flights, accommodation and airport transfers, for competitive prices. Not only is this making dental treatment more like a business product rather than healthcare, it also seems hard to refuse. Several studies have looked at patients travelling abroad for dental treatment and Milosevic claimed it is likely to increase in popularity due to cheaper treatment in Eastern Europe, high cost of private treatment in the UK and limited availability of NHS dentistry. ${ }^{16,19}$ As Holden explains, it is the norm for consumers to decide what brand of a particular product they want; however, when it comes to dentistry, the choice is more complicated. ${ }^{20}$ Thus, regardless of a patient's reasoning behind travelling for dental treatment, ultimately, dental patients are now consumers and can choose where they go and exactly what treatment they want.

With the ability of consumerist patients to now shop around for their dental treatment, one must consider if this puts a strain on the professional relationship between dentists and their patients. As Holden highlighted, once a patient is seen as a consumer, the 'clinicianpatient relationship begins to be transformed into a mere transaction, rather than one driven by professional duty. ${ }^{20}$ Consequently, as both dentist and patient compete with each other to achieve the best outcome for themselves (that is, patients looking for the best possible treatment at the lowest price and dentists trying to maximise their profits), ethics and professionalism fade away. ${ }^{20}$ Knowing that the appearance of a patient's smile is vital, are dentists using their position to sell treatments to patients they had not actually attended for? It is all too easy to see a patient for some basic fillings, but then tell them how easy it would be to transform their smile with some simple whitening they can do at home. Are we just as guilty as those abroad by offering attractive packages to patients to sell our treatments? Despite not having the appeal of a holiday included with the cost of treatment, we too have now commercialised our work.

\section{Problems for patients associated with dental tourism}

No matter how cheap and accessible these treatments seem to be, they may unfortunately come at a price, with unexpected complications. Lunt et al. ${ }^{16}$ described a patient who travelled to Hungary for dental implants, which were unsuccessful, and the patient ultimately had to spend over $£ 40,000$ on remedial treatment. ${ }^{16}$ Equally, patients who have had treatment in the UK are not always happy with the outcome; for example, in 2018/2019, the NHS received 14,000 complaints. ${ }^{21}$ The Dental Complaints Service reported 2,159 enquiries from patients wishing to complain about their private dental treatment in 2018.22 They also report that $85 \%$ of their complaints are due to what the patient perceives to be treatment failure. ${ }^{22}$ However, it is not easy for patients who had treatment abroad to complain if things go wrong and they want to take legal action. They may face some difficulties; for example, the consent form they have signed may claim that all legal proceedings should be in the country where treatment was undertaken. ${ }^{8}$ This would involve the patient having to return to the country, thus in effect defeating the object of having treatment abroad to save money. Several papers have highlighted the difficulties patients face if they want to bring about legal claims abroad. In Malaysia and Singapore, for example, it is completely given for clinicians to judge the quality of care and decide if there was a breach of duty. ${ }^{23}$ It has been reported by a Malaysian hospital that 'it never has been required to pay for a wrongful death, or negligence suit, ${ }^{23}$ thus making it difficult for patients abroad to prove malpractice. ${ }^{23}$ In India, although cases can be brought, it has been reported that $95 \%$ of cases are unsuccessful. ${ }^{16}$ This could be due to the deficiency of complaint procedures, as has been found by the Indian Health Ministry and the World Bank study. ${ }^{24}$ It has also been reported by a consumer advocacy group 'that patients claiming damages for medical 
negligence are often unable to prove their allegations because doctors are unwilling to testify against other doctors. ${ }^{24}$ Equally, it is difficult for patients to claim compensation in the UK because patients have to prove that the clinician breached their duty of care and that this breach of duty led to harm. ${ }^{25}$ Therefore, these difficulties for the patient having to prove negligence means they often receive no compensation. ${ }^{25}$

Also, the patient may not have the opportunity to report poor practice to a dental regulator because the country where they received treatment may not have professional regulators like in the UK. ${ }^{8,26}$ These patients would lose financially on the initial cost of their treatment, but if they return with complications such as infections, nerve injuries or failed restorations, they also potentially face further costs in paying for complex remedial treatment. ${ }^{7,27,28}$ The GDC $^{29}$ and NHS ${ }^{30}$ advise patients to be careful when deciding about travelling for their treatment, as not every regulator has the same standards as the GDC or GMC. The GDC will not have the authority to get involved with foreign clinicians who are not registered with it. ${ }^{29}$

When considering medico-legal issues, another challenge is that of language and the consent process. If there is a language barrier between the dentist and patient, it makes discussing treatment options, risks and benefits extremely difficult, so arguably, fully informed consent may not be obtained, ${ }^{31}$ which may have ramifications if the patient ever needed to take legal action.

Furthermore, these patients may face difficulties in that the dentist abroad may not accept responsibility for ongoing care. The clinics abroad may tell the patients they have been discharged from their care following treatment. Alternatively, they may offer the patient further treatment; however, this may include the costs of flights and accommodation. If patients seek help from a UK dentist, they may struggle to find someone who feels competent to address their concerns. They may visit a primary dental care provider who may find that the complications are beyond their skillset and outside their scope of practice, therefore referring the patient to secondary care or a private specialist. Although in both cases, dentists are obliged to act ethically and not breach their duty of care, it raises the question of what treatments we should offer and which treatments UK dentists would be happy to provide.

\section{Who is responsible?}

As a minimum, whether NHS or private, dentists should address any acute problems, such as pain or infection. ${ }^{32}$ However, one must consider who should pick up the tab for any remedial work required.

If a patient were to attend with failing implants, perhaps removal may be acceptable on the NHS, but surely not their replacement. Imagine the situation where a patient has had several implants placed abroad, but they have not been restored; would any dentist try to restore these for the patient? If a dentist in the UK accepted to restore them and they later fail, who is responsible? If no dentist was willing to restore them, could we really justify the surgical risk of removing them and starting the treatment again if the unrestored implants did not appear to be failing? It could be that we do not even recognise the implant system that has been used, even if we were willing to restore them. Even if the patient signed a disclaimer accepting that failure is a possibility, it would be difficult to prove whether the implant itself or the restoration is the reason for failure. Does the dentist's fear of litigation lead to the patient ending up in a half-treated difficult predicament?

The lack of guidelines on managing these patients puts clinicians in a dilemma both ethically and medico-legally. The study of Jeevan et al..$^{33}$ in 2011 demonstrated the impact medical tourism is having on plastic surgery units in the UK; it highlighted the need for guidance for NHS clinicians when faced with patients who have suffered complications from treatment undertaken abroad and has pushed the Department of Health to state clinicians' duties towards such patients. ${ }^{33}$ The NHS has stated that health providers should only address emergencies for such patients, but should not carry out any elective treatments. ${ }^{33}$

One must also consider if the NHS has a duty to educate the public and to what extent patients should take responsibility for themselves. However, as Hanefeld et al. ${ }^{1}$ quite rightly point out, the UK does not have any guidelines or regulations about patients choosing to have their treatment abroad ${ }^{1}$ and it is unlikely to happen because of the complexity of governing medical tourism. Furthermore, Beland and Zarzeczny highlighted that medical tourism has many stakeholders and factors with competing interests, thus making its regulation challenging. ${ }^{34}$ Therefore, how can clinicians be expected to advise patients about treatment abroad while they do not have the information themselves? Consequently, it could be argued that the lack of regulation and information is making patients vulnerable. If patients had treatment abroad and it went wrong, are they victims because we could not better advise them? Alternatively, if we were able to warn them of any potential problems, but they ignored our advice, surely then they would be responsible for their own decisions.

\section{Impact of dental tourism on the NHS}

Treating these patients on the NHS does not mean one treatment appointment only. They may need several treatments and then followups, which leads to no extra cost to the patient; however, some argue this is abusing the system. Patients may rely on the NHS as they know they can access it for free when they are back in the UK. ${ }^{33}$ Another concern has been raised as NHS resources are limited, so should they be being used on patients who have arguably sustained complications from procedures that UK clinicians would think avoidable if the treatment had been performed in the UK? It has been estimated by a cohort study over three years that the cost to the NHS for remedial treatment after cosmetic surgery abroad was an average of $£ 6,360$ per patient and ranged from $£ 114$ to $£ 57,968 .{ }^{35}$ Arguably, the harm from this cosmetic surgery or dental treatment abroad is self-inflicted, so raises the question if valuable NHS resources be used for this purpose. However, it could be difficult to enforce this, as equally, the same could be said about, for example, injuries from extreme sports; these are self-inflicted, yet the NHS pays for the treatment. Perhaps patients should be expected to subsidise their treatment costs or take out insurance that covers such complications.

\section{Impact on UK dentistry}

The increase of dental tourism has had a significant impact on UK dentistry. The founder of the UK cosmetic dentistry cost and clinic comparison website, Eoin Holohan, explains that dental tourism has created a competitive atmosphere that led to a noticeable drop in prices, especially dental implants that have been available for about $£ 995$ in the UK. ${ }^{36}$ This raises the question of how these implants are being offered at such a reduced rate, and we must consider if treatment standards and quality are being compromised in order to do this. For example, a study in Australia recorded 
that one of the reasons for dental implant failures that have been placed abroad were the implants themselves. 'The implant surfaces, when removed, appeared to have a green crust which was not removable and resembled copper corrosion, ${ }^{37}$ which had caused infection and full removal of the placed implants. ${ }^{37}$ Thus, for UK dentists to lower their prices, do we have to use products of lower quality or with less supporting clinical evidence, or are we having to cut corners? Some overseas countries do not have as rigorous cross-infection control procedures, and they have different sterilisation and hygiene processes, which result in fewer expenses for the clinic but can reduce the cost of treatment. ${ }^{37}$

Alternatively, are these clinics abroad able to provide cheaper treatments because they have more business? Perhaps their advertising regulations are not as stringent as in the UK, meaning a UK dentist can never compete with an overseas clinic when it comes to advertising. The Advertising Standards Authority (ASA) in the UK is responsible for monitoring and managing any inappropriate advertising deemed as 'misleading, harmful or offensive. ${ }^{16}$ Their scope includes websites, paid advertisements and social media, but is limited to advertisements in the UK. The ASA has previously ruled against some cosmetic surgery adverts, claiming they are 'irresponsible and misleading. ${ }^{16}$ After going through many overseas dental practice websites on the internet, it is easy to find many examples of what is prohibited in the UK. The GDC document Guidance on advertising clearly states dentists' duties to accurately market their treatments without any misleading statements. It emphasises the importance of ensuring patients are aware they may not be suitable for all treatment options and results advertised might not be the same for them. ${ }^{38}$

\section{Conclusion}

It is easy to see why patients are driven to seek dental treatment abroad. Dentistry is becoming increasingly consumer-driven around the world, including the UK, meaning patients will look around for the best deal. However, perhaps they travel oblivious to the potential consequences should things go wrong. When patients attend requiring remedial work, from an NHS point of view, we must consider which patients should take priority and assess how these limited resources should be allocated. From a dentist's point of view, the risk of litigation will always be a deciding factor as to whether they should carry out any remedial work, rather than just alleviating acute problems. More research is required to identify if dental tourism has the same financial impact on the NHS as failed cosmetic surgery done abroad, as well as collecting data on failure rates of overseas treatments in comparison to UK treatments and more accurate information on the cost of remedial dental treatment. We also need clearer guidelines on what dentists should offer these patients. It might be useful to introduce insurance schemes to cover any complications if treatment abroad goes wrong. However, not all treatment performed abroad goes wrong and, although somewhat controversial, it could be that foreign treatments might not actually be as bad as we think.

\section{Conflict of interest}

The authors declare they have no conflicting interests.

\section{References}

1. Hanefeld J, Horsfall D, Lunt N, Smith R. Medical tourism: a cost or benefit to the NHS? PLOS One 2013; DOI: 10.1371/journal.pone.0070406.

2. Donnelly L, Morley K. Soaring numbers flying abroad for medical care as NHS lists lengthen. The Telegraph (London) 2017 October 22.

3. Medigo. About Us. Available at https://www.medigo. com/about/ (accessed November 2020).

4. Buckland D. EXCLUSIVE 200,000 desperate Britons go ABROAD for medical care as NHS waiting lists spiral. Daily Express (London) 2015 April 24.

5. Wong K M, Musa G. Medical tourism in Asia: Thailand, Singapore, Malaysia, and India. In Hall M (ed) Medical tourism: the ethics, regulation, and marketing of health mobility. pp 167-186. London and New York: Routledge, 2012

6. Whittaker A. Pleasure and Pain: Medical Travel in Asia. Glob Public Health 2008; 3: 271-290.

7. Khan A, Reynolds L. Cut-price cosmetic surgery trips abroad could cost you dear. Express (London) 2016 April 21.

8. Turner L. Cross-border dental care: 'dental tourism' and patient mobility. Br Dent J 2008; 204: 553-554.

9. Lunt N, Horsfall D, Hanefeld J. Medical tourism: A snapshot of evidence on treatment abroad. Maturitas 2016; 88: 37-44

10. Jaapar M, Musa G, Moghavvemi S, Saub R. Dental tourism: Examining tourist profiles, motivation and satisfaction. Tour Manag 2017; 61: 538-552.

11. Lunt N, Smith R D, Mannion R et al. Chapter 12: Dental surgery case study. In Implications for the NHS of inward and outward medical tourism: a policy and economic analysis using literature review and mixed-methods approaches. Southampton: NIHR Journals Library, 2014

12. Leidig M. Tooth tourism transforms town as dental patients flock to Hungary. The Telegraph (London) 2002 October 6.

13. O'Neill T. UK's 'dental tourists' drive boom. 2006. Available at http://news.bbc.co.uk/2/hi/uk news/4872884.stm (accessed November 2020).

14. Lunt N, Smith R D, Mannion R et al. Chapter 14: Diaspora case study. In Implications for the NHS of inward and outward medical tourism: a policy and economic analysis using literature review and mixed-methods approaches. Southampton: NIHR Journals Library, 2014.
15. Calvasina P, Muntaner C, Quiñonez C. Transnational dental care among Canadian immigrants. Community Dent Oral Epidemiol 2015; 43: 444-451.

16. Lunt N, Smith R D, Mannion R et al. Implications for the NHS of inward and outward medical tourism: a policy and economic analysis using literature review and mixed-methods approaches. Southampton: NIHR Journals Library, 2014.

17. Hancocks S. Defensive dentistry. Br Dent J 2005; 199: 543.

18. Westgarth $D$. Risk taking: Is defensive dentistry rife in the UK? BDJ In Pract 2019; 32: 8-12.

19. Milosevic A. Dental Tourisma Global Issue? J Esthet Restor Dent 2009; 21: 289-291.

20. Holden A C L. Consumer-driven and commercialised practice in dentistry: an ethical and professional problem? Med Health Care Philos 2018; 21: 583-589.

21. Large A. Top five reasons for dental complaints treatment issues. 2020. Available at https://www. dentistry.co.uk/2020/03/16/top-five-reasons-dentalcomplaints-treatment-issues/ (accessed November 2020).

22. Dental Complaints Service. Dental Complaints Service Review 2015-2018. 2019. Available at https://www. gdc-uk.org/docs/default-source/dcs/dental-complaintsservice-review-2015-2018.pdf (accessed November 2020)

23. Cortez N. Patients without Borders: The Emerging Global Market for Patients and the Evolution of Modern Health Care. Ind Law J 2007; 83: 71-132.

24. Mudur G. Indian doctors not accountable, says consumer report. BMJ 2000; 321: 588

25. Jackson E. Medical Law. Text, Cases and Materials. 4th ed. Oxford: Oxford University Press, 2016.

26. Pollard K. When Cosmetic Surgery Abroad Goes Wrong... Who Pays? 2017. Available at https://www. imti.com/blog/when-cosmetic-surgery-abroad-goeswrong\%E2\%80\%A6-who-pays/ (accessed November 2020)

27. Burke F. The perils of dental tourism. Dent Update 2007 34: 605.

28. O'Connell B, O'Sullivan M. Have teeth will travel: dental tourisminforming the public. JIr Dent Assoc 2007; 53: 180.

29. GDC. Going abroad for your dental care? 2019. Available online at https://www.gdc-uk.org/ information-standards-guidance/information-ondental-treatment/going-abroad-for-dental-treatment (accessed November 2020)

30. NHS. Cosmetic surgery abroad. 2019. Available at https://www.nhs.uk/conditions/cosmeticprocedures/cosmetic-surgery-abroad/ (accessed November 2020).

31. Dental Protection. Dental tourism: home and away. 2014. Available at https://www.dentalprotection.org/ uk/articles/dental-tourism-home-and-away (accessed November 2020).

32. Asai R G, Jones Jr K D. Am I Obligated To Treat A Patien Whose Need For Emergency Care Stems From Dental Tourism? J Am Dent Assoc 2007; 138: 1018-1019.

33. Jeevan R, Birch J, Armstrong A P. Travelling abroad for aesthetic surgery: Informing healthcare practitioners and providers while improving patient safety. J Plast Reconstr Aesthet Surg 2011; 64: 143-147.

34. Béland D, Zarzeczny A. Medical tourism and national health care systems: an institutionalist research agenda. Global Health 2018; 14: 68

35. Miyagi K, Auberson D, Patel A J, Malata C M. The unwritten price of cosmetic tourism: An observational study and cost analysis. J Plast Reconstr Aesthet Surg 2012: 65: 22-28.

36. International Medical Travel Journal. Claims that UK dental tourism is falling as UK dentists offer better value. 2014. Available at https://www.imtj.com/news/ claims-uk-dental-tourism-falling-uk-dentists-offerbetter-value/ (accessed November 2020).

37. Barrowman R A, Grubor D, Chandu A. Dental implant tourism. Aust Dent J 2010; 55: 441-445.

38. GDC. Guidance on advertising. 2013. Available at https://www.gdc-uk.org/docs/default-source/ guidance-documents/guidance-on-advertising.pdf (accessed November 2020). 